\title{
Exploring the Mediating Effect of KMPC on PM and OP in the Education Sector
}

\author{
* Mahwash Ghafoor Chaudhry (Corresponding Author) \\ ** Dr. Samina Nawab \\ *** Dr. Khuram Shafi
}

\begin{abstract}
The basic objective of this research study is to determine the impact Performance Management (PM) has on the overall performance of the organizations in the education sector of Pakistan. The study also seeks to explore the role of Knowledge Management Process Capabilities (KMPC) by Gold, Malhotra, \& Segars (2001) acting as a mediator on the relationship between Performance Management (PM) and Organizational Performance (OP). Research methodology based on the quantitative approach uses a multi-itemed questionnaire to collect the data. The data reliability is tested using Cronbach Alpha and in addition to the regression, correlation analysis, and the Baron and Kenny mediation procedure. The result of the study indicates the presence of a relationship between PM and OP being partially mediated by KMPC. Knowledge management (KM) needs to focus and be linked with PM when positive results are expected to be delivered by the organization in the form of improved performance. KM process seeks to identify and explain the mechanism or process underlies the relationship between $P M$ and $O P$ and hence needs to be embedded within the $P M$ cycle which applies to the overall performance of the organization.
\end{abstract}

Keywords: Performance Management, Knowledge Management, Performance, Knowledge Process Capabilities

\section{Introduction}

PM is one of the essential processes that organizations must adopt to get optimize performance and attain the organizational goal. However, researchers believe that if PM systems are planned and executed purposely it will cause long-term encouraging and motivating impact on an individual's performance. All the organizations must have a PM system to assess employees and to design the 'Knowledge Management System' to attain organizational objectives in true spirit. The concept of KM is not something new it aroused almost two decades ago. Davenport (1994) initially defined this concept as describing KM as a process involving knowledge confining, sharing, and effective usage. Especially for the organizations that are in pursuit of improved performance, knowledge is an essential intermediary product (Ichijo \& Nonaka, 2006). A high level of performance at the organizational level can be achieved through the KM. Investment by organizations on the initiative is determined by strategic imperatives depending upon effective KM resources so that knowledge capability can be built to enhance the flow of information and knowledge inside the organization and also for effective management. The resources which are being enhanced include the infrastructure of technology, structure, and culture of the organization as these are connected to the firm's knowledge infrastructure capability. The acquisition, conversion, application, and protection of knowledge eventually affect the knowledge process capability of the firm (Alavi \& Leidner, 2001; Gold, Malhotra, \& Segars, 2001) providing different measures to assess the performance of the firm. An exploratory investigation based on the survey of ninety organizations found that KM practices were directly linked with OP and most importantly related to the financial performance (McKeen, Zack, \& Singh, 2006). This research explores the relationship between PM and OP mediated by the KMPC. $\mathrm{KM}$ ensures that teams and individuals know to make their work easier which eventually leads to

\footnotetext{
* Department of Management Sciences, COMSATS University Islamabad, Wah Campus, Pakistan

Email: mahwashchaudhry@ hotmail.com

** Department of Management Sciences, COMSATS University Islamabad, Wah Campus, Pakistan Email: samina@ciitwah.edu.pk

*** Department of Management Sciences, COMSATS University Islamabad, Wah Campus, Pakistan Email: shafikhuram@yahoo.com
} 
improved performance. In other words, knowledge feeds performance and is also derived from it. Because of the strong link that exists between $\mathrm{KM}$ and performance, it is fairly suitable to suggest that $\mathrm{KM}$ and PM will also be strongly linked. The more the knowledge the better will be performance and the more one learns from performance greater will be knowledge. The present study proposes that KMPC mediates the relationship between PM and OP.

\section{Literature Review}

\section{Performance Management (PM)}

Through the process of PM the individual, as well as team performance, can be improved systematically (Armstrong, 2006). Though the basic aim of the PM is an improvement in business performance it can stay effective as long as organization employees and managers do not take it as a burden (Pulakos \& O'Leary, 2011). To perform well employees need to have clear and well-defined goals about their work (Buchner, 2007). PM is also supported by control theory which argued that it is a comparative process to minimize the differences between the standard and observed behaviors (Carver \& Scheier, 1981). According to control theory, feedback shaped behavior and also provides a basis for assessment of feedback elements (Buchner, 2007). Buchner (2007) stated that gaps are present between theories and PM system which are used in practice which means that the system of PM should be redesigned goals mechanism including goal specificity and proper or timely feedback for effective process and performance of the employees.

\section{Organizational Performance $(O P)$}

Presenting an idiosyncratic view of reality, Performance explains numerous critical thoughts and measuring instruments on the concept (Elena-Iuliana \& Maria, 2016). Organizations viewed as a social system takes into account means as well as ends is called Performance (Robbins, 1987). Viewing performance in the context of the public sector, it is described as the outcome of an adequate, efficient, and effective budgetary process that involves the presence of relationship among objectives, means, and ends (Profiroiu, 2001). Public sector performance is not just related to the financial aspects alone but it also includes the accomplishment of both environmental and social equity objectives which are deemed essential for a smooth system transition from the 3E (effectiveness, efficiency, economy) (Chai, 2009) to a 5E-type system (economy, efficiency, effectiveness, environment and equity) (Bi, Davidson, Kam, \& Smyrnios, 2013). However, items such as evaluation, piloting efficiency, effectiveness, and quality can be viewed as a means for the achievement of the very definition of the performance (Bartoli \& Blatrix, 2015). Research on PM in Standard Chartered Bank Limited in Kenya on the improvement of the OP finds that the impact of the PM system on product innovation has increased to a great extent along with other factors yet retention of top performers got a lower ranking (Waka, 2010). Therefore present research suggests the following hypothesis to be tested in support of the literature discussed.

\section{H1: $P M$ is significantly related to $O P$}

\section{Knowledge Management (KM)}

$\mathrm{KM}$ process is described a focused and continuous network of communications conducted by the people to manage actions, components, and other individuals involved in core knowledge practices and procedures resulting in the cohesive, directed, and organized circle that acquires, improves, sustains, develops, and transmits knowledge base of the enterprise (Firestone, 2001). In KM related literature Gold et al (2001) presented the KM capabilities model viewed by the researchers as one of the most significant and cited models. The knowledge dimensions in this model are acquisition, application, conversion, and protection of knowledge. This link of knowledge capabilities to the OP has been previously researched by other researchers in past (Chan \& Chao, 2008; Jennex \& Olfman, 2005; Laframboise, Croteau, Beaudry, \& Manovas, 2007). A positive relationship has been reported by Gold et al. (2001) between OP and process capabilities, though different relationships existing between process capabilities dimensions and OP are not thoroughly studied and explored (Law, Wong, \& Mobley, 1998).

Knowledge Management Process Capability (KMPC)

According to Gold et al. (2001), there are four dimensions of the KMPC which are discussed below.

Knowledge Acquisition: Acquisition means the ability of an organization to identify, obtain and collect knowledge that is it needs and is important for conducting various operations and activities (Gold et al., 2001; Zahra \& George, 2002). Previous research supports the presence of an affirmative and strong link of OP with the acquisition of knowledge. Knowledge creation practices are 
significantly linked to organizational improvements (Song, 2008). A direct and strong relationship does exist between OP and knowledge acquisition, given that the application and usage of knowledge is done in an organized and appropriate manner (Seleim \& Khalil, 2007).

Knowledge conversion: Business needs to convert the knowledge it acquires from either internal or external sources in a useful and effective way so the organization can gain maximum benefits from it. (Lee \& Suh, 2003). Knowledge and information are temporary and short time in nature so organizations should vigilant in converting raw data (facts and figures) into useful information and speed up the process of conversion of raw data to useful knowledge for their benefits (Bhatt, 2001).

Knowledge application: It is described as a process by which the organization adapts the most relevant and active means of applying useful knowledge for creating values for itself (Bhatt, 2001). Knowledge application of the products and services that a firm offers is necessary for value maximization and organizations encourage such programs where employees and teams apply their knowledge for the development of a new product for the goal of enhancement of performance to speed up the market and make innovations (Sarin \& McDermott, 2003). Organizations generate knowledge rapidly at a comparatively low cost through its competitive advantage, making efficient and effective implications (Dröge, Claycomb, \& Germain, 2003).

Knowledge protection: Protection and security of knowledge are vital for efficacious control and functioning in the organizations. Information Technology systems use file names, user names, protocols for file sharing, and passwords for authorized users and to protect and secure knowledge (Chyi Lee \& Yang, 2000). Protection of knowledge should not be neglected (Gold et al., 2001) and its protection from inappropriate and illegal use is necessary for the business to make and sustain the competitive advantage (Liebeskind, 1999). Knowledge is critical for gaining a competitive edge and its storage and protection are considered to maximize the organization's value (Lee \& Sukoco, 2007).

\section{$P M$, OP mediated by KMPC}

In simple words, we can call OP as the aggregate outcome from an organization's activities with organizational strategies and activities affecting performance in different dimensions (Lumpkin \& Dess, 1996; Ray, Barney, \& Muhanna, 2004). Knowledge is a strategic resource of the organization can improve its firm performance (Miles \& Snow, 1994). A study investigating the effect of Knowledge Management Capabilities on OP found a direct and significant association exists between the structure and culture of the organization and acquisition, application, and protection of knowledge with OP (Matin \& Sabagh, 2015). Knowledge resources for example structure of organization and application of knowledge are directly linked with OP. Yet others are not directly related such as technology and knowledge conversion. This means that though the knowledge management capabilities construct are determined by the individual resources as a whole, but all of them are not directly related to OP (Mills \& Smith, 2011). According to Seleim \& Khalil (2007) out of five knowledge processes capabilities, only the application of knowledge was directly linked to OP. A study on the relationship between KM and performance improvement in organizations showed that dimensions of $\mathrm{KM}$ are good indices for evaluating the contribution of $\mathrm{KM}$ to performance improvement (Boumarafi \& Jabnoun, 2008). Research identifies the importance of KM activities in the performance appraisal system in the UK consultancy sector. All KM activities proposed by previous literature are essential in their performance appraisals yet at varied weights (El-Farr, 2011). Performance review which is a part of the PM was found to be positively related to the sharing of knowledge yet PM's impact on knowledge sharing was partially supported (Horvat, Sharma, \& Bobek, 2015). Tacit knowledge management holds a significant impact on the OP, though among all dimensions yet only two dimensions namely socialization and internalization significantly complement OP (Muthuveloo, Shanmugam, \& Teoh, 2017). A research model is proposed by the researchers that supports the relationship between KM enabling factors and OP mediated by the knowledge creation process (Abubakar, Elrehail, Alatailat, \& Elçi, 2017). High performance work system is positively linked with OP with KM as a mediator (Jyoti \& Rani, 2017). A study evaluating the role of $\mathrm{KM}$ as a mediator on organizational learning culture (OLC) in the perspective of OP found that organizational learning culture is imperative to carry out KM effectively also OLC has a strong impact on achieving OP (Wahda, 2017). As KM is vital for the continuous improvement in performance because due to knowledge organizations can identify, examine and capture the opportunities in the market resulting in cause the better and improved performance of the organizational employees (Massingham, 2004). In this study KMPC is the mediating factor between 
the PM and OP suggesting the following hypothesis to be tested after the establishment of a significant relationship between OP and PM.

H2: KMPC acts as a mediator between PM and OP

\section{Research Model}

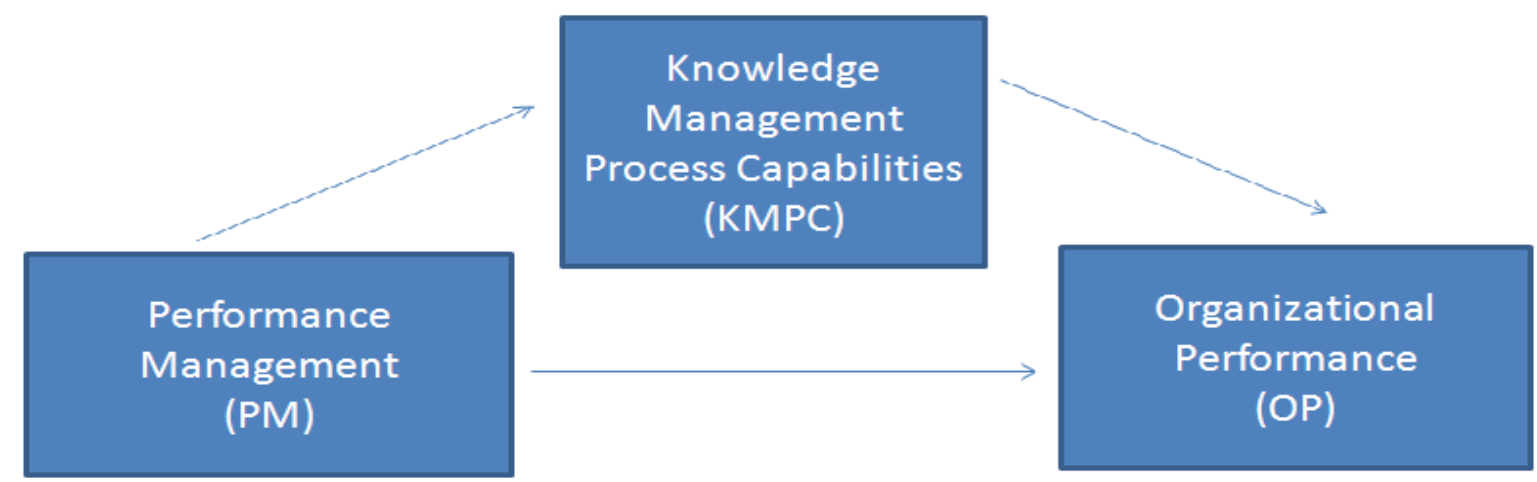

Research Methodology

Present research uses quantitative research methodology. The study uses a multiple itemed questionnaire constructed on a (six-point) Likert scale. This scale ranges from "strongly disagree" indicated by "1" and strongly agree" denoted by " 6 ". The questionnaire included the items measuring PM, adopted from the dimensions of the questionnaire developed by Marsick and Watkins (2003) known as learning organization questionnaire (DLOQ) and it consists of forty-three items. The items for the KMPC have been adopted from a study used and validated by Nonaka, Toyama, \& Konno, (2000). The study found that the construct of knowledge creation is made up of conversion processes of knowledge including socialization, externalization, combination, and internalization. whereas the items of OP have been adopted from a study that also used the item of knowledge creation previously used to propose a model for research that interconnects the KM factors (Lee \& Choi, 2003). The items for OP have been adopted from the research work of Deshpande, Jarley, \& Webster (1993) and Drew (1997). After making some minor changes to the questionnaire the questionnaire was administered for pilot testing and doing the factor analysis of items included in the questionnaire based on the KaiserMeyer-Olkin (KMO) is used to measure the adequacy of sampling collected, to check if there are small partial correlations among variables. The value of the KMO test should be greater than 0.5 for conducting further analysis. Results show that the value of KMO was greater than 0.5 for all three variables. To find out if the correlation matrix is an identity matrix, the present study uses Bartlett's test of sphericity. It indicates if the factor model is not suitable and is considered significant if it is less than 0.05 (level of significance). Our results meet the desired conditions of the KMO and Bartlett test and finally, a questionnaire based on 26 items was finalized. The pilot testing data also confirmed the data reliability using Cronbach alpha where all the items under PM, KMPC, and OP were greater than 0.7 value of Cronbach alpha.

\section{Sample}

The present study attempts to understand the influence PM has on OP and the mediation effect of KMPC on the relationship between PM and OP from the perspective of the education sector focusing specifically on the public sector universities of Pakistan. The questionnaires were self-administered and a total of 150 usable questionnaires were then used for further analysis and interpretation from a total of 250 questionnaires. The questionnaires were filled by the teaching as well as non-teaching staff of the sample universities. The respondents belonged from different academic departments of these universities, from Engineering, Management, Mathematics and Finance departments of the sample universities.

\section{Results}

The reliability is a sign of constancy and steadiness of an instrument to measure the concept and determine the goodness of a measure (Sekran, 2003). All three variables are found to be reliable with the values of Cronbach alpha greater than 0.7. Cronbach's coefficient alpha is the most popular and frequently used test to evaluate the data reliability (Cronbach's alpha; Cronbach, 1946). It is used for multipoint-scaled items, which indicates that the ability of the instrument to provide better results depends on the higher level of the coefficients (Sekran, 2003). Following are the result of the reliability analysis using the standard of Cronbach alpha (Table I) 
Table 1. Reliability Analysis

\begin{tabular}{ll}
\hline Variables & Cronbach alpha \\
\hline PM & .89 \\
Knowledge management Process Capability & .83 \\
Organizational performance & .89 \\
\hline
\end{tabular}

The descriptive statistics give brief information on descriptive coefficients by summarizing the given data set. It gives the extent of variability such as central tendencies and dispersions of both the dependent and independent variables (Sekran, 2003). The descriptive statistics for the present study data indicate that for the variable of PM the mean value is 3.8001 and the standard deviation is 1.06580. For KMPC, the mean value is 3.7709 , and the standard deviation found to .66365 and for the dependent variable of OP the mean value is found to be 3.6053 and the value of standard deviation is 1.49072 .

\section{Correlation Analysis}

To understand the way all the variables relate with one another and the nature, significance, and direction of the bivariate relationship among variables correlation test is conducted on the present data given in Table 2. According to correlation results, there is significant as well as positive correlation at the significance level of 0.01 , among all three variables namely PM, KMPC, and OP.

Table 2. Correlation Analysis

\begin{tabular}{llll}
\hline & PM & KMPC & OP \\
\hline PM & 1 & \\
KMPC & $.464(* *)$ & 1 \\
OP & $.396(* *)$ & $.577(* *)$ & 1 \\
\hline & $* *$ & Correlation is significant at the 0.01 level (2-tailed).
\end{tabular}

The value of the correlation between PM denoted by PM and KMPC in the table above is .464, as for the bivariate relationship between PM and OP denoting OP the value of the correlation coefficient is .396. As far as the association between KMPC and OP are concerned their correlation value is .577 which shows that a strong positive correlation exists between them. The correlation value between all three is between the range of +1 and -1 and the sign of all the three correlation results values is positive showing a positive association among them.

\section{Regression Analysis}

The present study proposes the hypothesis that there exists a mediation effect of variable KMPC between the PM and OP. A hypothesized causal chain where the first variable has an effect on a second variable and which in turn affects the third variable is known mediation. Similarly, we hypothesize that PM effects KMPC which in turn has an impact on OP. Baron and Kenny (1986) describe the procedures which are used to evaluate various meditational hypothesis. Judd and Kenny (1981), and James and Brett (1984) discussed the same four steps involved in mediation. Accordingly, the first step the independent variable which is PM in our study is as checked for association with the dependent variable of organizational performance. This test is essential for the establishment of an effect that may be mediated by another variable. Table 3 gives the results of a direct effect of PM on OP.

Table 3. Effect of PM and OP (Mediation procedure step 1)

\begin{tabular}{llllllll}
\hline & R & R2 & S.E. & ANOVA & Beta & t-value & P-value \\
\hline PM $-\rightarrow$ OP & $.39^{`}$ & .15 & $1.3^{`}$ & .000 & .55 & 5.224 & .000 \\
\hline
\end{tabular}

As the results in Table 3 show that the P-value is less than 0.05 , so there is a significant relationship between PM and OP. The value of R square is. 15 which indicates that $15 \%$ of variation in OP is due to the PM variable. The value of the beta coefficient is 0.55 since the t-test is significant so the beta is also statistically significant and can be interpreted as for every unit of increase PM, OP increases by 
55\%. In the second step, the independent variable which is PM is tested for correlation with the mediator variable of KMPC as given in Table 4. This step according to Baron and Kenny (1986) treats the mediator as the outcome variable.

Table 4. Effect of PM and KMPC (Mediation procedure step 2)

\begin{tabular}{llllllll}
\hline & R & R2 & S.E. & ANOVA & Beta & t-value & P-value \\
\hline PM $\rightarrow$ KMPC & .57 & .33 & 1.2 & .000 & 1.29 & 8.85 & .000 \\
\hline
\end{tabular}

Here we can see that there is a significant value of $\mathrm{P}$ which is less than 0.05 . The value of $\mathrm{R}$ square is .33 which indicates that PM accounts for 33\% of explained variation in KMPC. The value of the beta coefficient is 1.29. The third step of the mediation procedure calls for testing the correlation between the mediating variable, which is KMPC and the dependent variable of OP, the results of this step are given in Table 5 below. According to Baron and Kenny (1986), the first variable must be controlled when establishing the correlation between the remaining two variables. Following are the results of the third step

Table 5. Effect of KMPC and OP (Mediation procedure step 3)

\begin{tabular}{llllllll}
\hline & R & R2 & S.E. & ANOVA & Beta & t-value & P-value \\
\hline KMPC $-\rightarrow$ OP & .57 & .32 & 1.2 & .000 & 1.2 & 8.0 & .000 \\
\hline
\end{tabular}

As the results of the third step indicate that the results of the regression output are significant at 0.05 (level of significance). The value of R square is 0.32 which explains that the KMPC accounts for $32 \%$ of explained variation in OP. And the value of Beta, in this case, is 1.2 which means that for every unit change in KMPC the OP increases by a value of 1.2. In the fourth step under the Baron and Kenny mediation procedure, the analysis encompasses the formation of complete mediation throughout all the variables. To establish complete mediation, the independent variable must have zero effect on the dependent variable while controlling for the mediator variable which is KMPC. However, if only the first three-step are satisfied under the Baron and Kenny (1986) mediation procedure then there is partial mediation. Only the first three steps satisfy the conditions posed by the mediation procedure. So, KMPC has partially mediated the impact of PM and organizational learning. Thus KMPC has a significant relationship with both PM and OP (Firestone, 2001), also consistent with results in previous research of real-life case studies such as Bartlett (1996) and with research findings such as that of Tseng (2010) and O'Dell \& Hubert (2011).

\section{Discussion}

The present study attempts to explore the impact of PM on OP mediated by the KMPC in the context of educational institutions in Pakistan. The results of the analysis show a partial mediating effect of KMPC on PM and OP relationship. These findings are supportive of three out of four hypotheses. The results are supported by another study where the dimensions of Organizational Learning are found to positively predict performance and knowledge management practices of an organization (Njuguna, 2009) and by previous research, conducted on 581 business firms listed at Lahore Stock Exchange (LSE), where KMPC have a cumulative positive along with significant effect on OP with two KMPC externalization and internalization having a significant along with the positive impact on the creativity of the organization which in turn leads to a positive effect on OP.

\section{Implications, Limitations, and Future Research}

This study proposes several implications by focusing on PM in organizations that can have a strong influence on the KMPC and OP. So, due consideration should be given to the incorporation of PM in all activities related to KMPC to ensure enhancement in the organizational performance. The results suggest that organizations need to invest more in the creation, sharing, and storing of knowledge in organizations as well as the coordinating activities, people, and other components to enhance OP. However, in Pakistan, organizations and its members tend to focus more on the management of explicit knowledge rather than tacit knowledge (Shahzad, Bajwa, Siddiqi, Ahmid, \& Raza Sultani, 2016). The present study is subjected to a few limitations as well. Current research has a small sample size as only two universities have been included in the sample, more accurate results could be drawn with a larger sample size and better generalizations can be done. The PM one of the most significant and vital dimensions of organizational learning is measured through dimensions of the questionnaire developed by Marsick \& Watkins (2003) namely the Learning Organization Questionnaire (DLOQ). Among all of the dimensions of DLOQ, this study has focused on just one dimension that is of PM. Future research studies are suggested to focus on exploring the relationship of other dimensions of organizational learning with the performance of organization and study these relationships for 
complete or partial mediation by KMPC. The present study has Nonaka \& Takeuchi (1995) has used the framework of knowledge processing capabilities but better results could be produced in the future by evaluating the mediation effect of each capability on the PM and OP. Moreover, future research could attempt to measure the benefits the organizations can derive from PM and KM towards OP tangibly as traditional measures of accounting are denominated in a currency based on the worth of tangible assets, it is important to identify these relationships between PM, KM and OP using tangible measures as intangibles measures focusing internally with limited value to compare multiple companies. Also the investors and stock holders recognize the performance and value of organizations expressed in terms of currency based on generally accepted techniques (Nold, 2011). The relationship between PM, KMPC, and OP, that can further be explored in combination with other variables as well organizational contexts.

\section{References}

Abubakar, A. M., Elrehail, H., Alatailat, M. A., \& Elçi, A. (2017). Knowledge management, decisionmaking style, and organizational performance. Journal of Innovation \& Knowledge.

Alavi, M., \& Leidner, D. E. (2001). Knowledge management and knowledge management systems: Conceptual foundations and research issues. MIS Quarterly, 107-136.

Armstrong, M. (2006). Performance management: Key strategies and practical guidelines. London, UK: Kogan Page Limited.

Bartlett, C. A. (1996). McKinsey \& Company: Managing knowledge and learning. Harvard Business School.

Bartoli, A., \& Blatrix, C. (2015). Management dans les organisations publiques: De fis et logiques d'action. Paris: Dunod.

Bhatt, G. D. (2001). Knowledge management in organizations: examining the interaction between technologies, techniques, and people. Journal of Knowledge Management, 5(1), 68-75.

Bi, R., Davidson, R., Kam, B., \& Smyrnios, K. (2013). Developing organizational agility through IT and supply chain capability. Journal of Global Information Management, 21, 38-55.

Boumarafi, B., \& Jabnoun, N. (2008). Knowledge management and performance in UAE business organizations. Knowledge Management Research \& Practice, 6(3), 233-238.

Buchner, T. W. (2007). Performance management theory: A look from the performer's perspective with implications for HRD. Human Resource Development International, 10(1), 59-73.

Carver, C. S., \& Scheier, M. F. (1981). Attention and self-regulation: A control-theory of behavior. The self and social life. New York: Springer-Verlag.

Chai, N. (2009). Sustainability Performance Evaluation System in Government. A Balanced Scorecard Approach Towards Sustainable Development. London: Springer.

Chan, I., \& Chao, C. (2008). Knowledge management in small and medium-sized enterprises. Communications of the ACM, 51(4), 83-88.

Chyi Lee, C., \& Yang, J. (2000). Knowledge value chain. Journal of Management Development, 19(9), 783-794.

Davenport, T. H. (1994). Saving IT's soul: Human-centered information management. Harvard Business Review, 72(2), 119-131.

Dröge, C., Claycomb, C., \& Germain, R. (2003). Does knowledge mediate the effect of context on performance? Some initial evidence. Decision Sciences, 34(3), 541-568.

El-Farr, H. (2011). Linking performance appraisal to knowledge management activities in the management consultancy sector in the UK. Leeds University Business School.

Elena-Iuliana, I., \& Maria, C. (2016). Organizational Performance - A concept that self-seeks to find itself PERFORMANCE-A CONCEPT THAT SELF-SEEKS TO FIND ITSELF. Annals of'Constantin Brancusi'University of Targu-Jiu. Economy Series, 4.

Firestone, J. M. (2001). Estimating the benefits of knowledge management initiatives: concepts, methodology, and tools. Journal of the KMCI, 1(3), 110-129.

Gold, A. H., Malhotra, A., \& Segars, A. H. (2001). Knowledge management: An organizational capabilities perspective. Journal of Management Information Systems, 18(1), 185-214.

Horvat, J., Sharma, K., \& Bobek, S. (2015). Knowledge sharing and performance appraisal of employees: a pilot case study. Review of Integrative Business and Economics Research, 4(6273).

Ichijo, K., \& Nonaka, I. (2006). Knowledge creation and management: New challenges for managers. 
Oxford university press.

Jennex, M., \& Olfman, L. (2005). Assessing knowledge management success. International Journal of Knowledge Management (IJKM), 1(2), 33-49.

Jyoti, J., \& Rani, A. (2017). High-performance work system and organizational performance: role of knowledge management. Personnel Review, 46(8), 1770-1795.

Laframboise, K., Croteau, A., Beaudry, A., \& Manovas, M. (2007). Interdepartmental knowledgetransfer success during information technology projects. International Journal of Knowledge Management, 3(2), 47-67.

Law, K. S., Wong, C. S., \& Mobley, W. M. (1998). Toward a taxonomy of multidimensional constructs. Academy of Management Review, 23(4), 741-755.

Lee, H., \& Choi, B. (2003). Knowledge Management Enablers, Processes, and Organizational Performance: An Integrative View and Empirical Examination. Journal of Management Information System, 20(1), 179-228.

Lee, H. S., \& Suh, Y. H. (2003). Knowledge conversion with information technology of Korean companies. Business Process Management Journal, 9(3), 317-336.

Lee, L. T. S., \& Sukoco, B. M. (2007). The effects of entrepreneurial orientation and knowledge management capability on organizational effectiveness in Taiwan: the moderating role of social capital. International Journal of Management, 24(3), 549.

Liebeskind, J. P. (1999). Knowledge, strategy, and the theory of the firm. In Knowledge and Strategy, 197-219.

Lumpkin, G. T., \& Dess, G. G. (1996). Clarifying the entrepreneurial construct and linking it to performance. Academy of Management Review, 21(1).

Marsick, V. J., \& Watkins, K. E. (2003). (2003). Demonstrating the value of an organization's learning culture: the dimensions of the learning organization questionnaire. Advances in Developing Human Resources, 5(2), 132-151.

Massingham, P. (2004). Linking business level strategy with activities and knowledge resources. Journal of Knowledge Management, 8(6), 50-62.

Matin, E. K., \& Sabagh, P. (2015). Effects of Knowledge Management Capabilities on Organizational Performance in Iranian Export Companies., 6(2), 240. Mediterranean Journal of Social Sciences, 6(2), 240-250.

McKeen, J. D., Zack, M. H., \& Singh, S. (2006). Knowledge management and organizational performance: an exploratory survey. In System Sciences, 2006. HICSS'06. Proceedings of the 39th Annual Hawaii International Conference on (p. 152b-152b). IEEE.

Miles R. E., \& Snow, C. C. (1994). Organizational Strategy, Structure, and Process. New York: McGraw-Hill.

Mills, A., \& Smith, T. (2011). Knowledge management and organizational performance, a decomposed view. Journal of Knowledge Management, 15(1), 156-171.

Muthuveloo, R., Shanmugam, N., \& Teoh, A. P. (2017). The impact of tacit knowledge management on organizational performance: Evidence from Malaysia. Asia Pacific Management Review, 22(4), 192-201.

Njuguna, J. I. (2009). Strategic positioning for sustainable competitive advantage: an organizational learning approach. KCA Journal of Business Management, 2(1).

Nold, H. A. (2011). Making knowledge management work. Knowledge Management Research \& Practice, 9(1), 84-94.

Nonaka, I., \& Takeuchi, H. (1995). The knowledge creation company: how Japanese companies create the dynamics of innovation. Oxford university press.

Nonaka, I., Toyama, R., \& Konno, N. (2000). SECI, Ba, and leadership: A unified model of dynamic knowledge creation. Long Range Planning, 33, 5-34.

O'Dell, C., \& Hubert, C. (2011). Building a knowledge-sharing culture. The Journal for Quality and Participation, 34(2), 22-26.

Profiroiu, M. (2001). Managementul organizatiilor publice ('The management of public organisations"). Bucuresti: Editura Economica.

Pulakos, E. D., \& O'Leary, R. S. (2011). Why is performance management broken? Industrial and Organizational Psychology, 4(2), 146-164.

Ray, G., Barney, J. B., \& Muhanna, W. A. (2004). Capabilities, business processes, and competitive 
advantage: choosing the dependent variable in empirical tests of the resource-based view. Strategic Management Journal, 25, 23-37.

Robbins, S. P. (1987). Organizational Theory: Structure, Design, and Application, 1987, San Diego: Prentice-Hall.

Sarin, S., \& McDermott, C. (2003). The effect of team leader characteristics on learning, knowledge application, and performance of cross-functional new product development teams. Decision Sciences, 34(4), 707-739.

Seleim, A., \& Khalil, O. (2007). Knowledge management and organizational performance in the Egyptian software firms. International Journal of Knowledge Management (IJKM), 3(4), 3766.

Shahzad, K., Bajwa, S. U., Siddiqi, A. F. I., Ahmid, F., \& Raza Sultani, A. (2016). Integrating knowledge management (KM) strategies and processes to enhance organizational creativity and performance: an empirical investigation. Journal of Modelling in Management, 11(1), $154-179$.

Song, J. H. (2008). The key to organizational performance improvement: A perspective of organizational knowledge creation. Performance Improvement Quarterly, 21(2), 87-102.

Tseng, C. C. (2010). The effects of learning organization practices on organizational commitment and effectiveness for small and medium-sized enterprises in Taiwan. University of Minnesota.

Wahda. (2017). Mediating effect of knowledge management on organizational learning culture in the context of organizational performance. Journal of Management Development, 36(7), 846858.

Waka, L. A. (2010). The relationship between the performance management system and organizational performance at the Standard Chartered Bank Kenya Limited. University of Nairobi, Kenya.

Zahra, S. A., \& George, G. (2002). Absorptive capacity: a review, conceptualization, and extension. Academy of Management Review, 27(2), 185-204. 